\title{
Haemodynamic effects of plasma-expansion with hyperoncotic albumin in cirrhotic patients with renal failure: a prospective interventional study
}

\author{
Andreas Umgelter*1, Katrin Wagner ${ }^{2}$, Wolfgang Reindl ${ }^{1}$, Nils Nurtsch ${ }^{1}$, \\ Wolfgang Huber ${ }^{1}$ and Roland M Schmid ${ }^{1}$
}

Address: ${ }^{1}$ II. Medizinische Klinik, Klinikum rechts der Isar der Technischen Universität München, Ismaninger Str. 22, D-81675 München, Germany and ${ }^{2}$ Klinik für Kardiologie, Städtisches Klinikum Bogenhausen, Englschalkinger Str. 77, D-81925 München, Germany

Email: Andreas Umgelter* - andreas.umgelter@lrz.tu-muenchen.de; Katrin Wagner - katrinwagner73@hotmail.com; Wolfgang Reindl - wolfgang.reindl@lrz.tu-muenchen.de; Nils Nurtsch - nils.nurtsch@gmx.de; Wolfgang Huber - wolfgang.huber@lrz.tumuenchen.de; Roland M Schmid - roland.schmid@Irz.tu-muenchen.de

* Corresponding author

Published: 27 August 2008

BMC Gastroenterology 2008, 8:39 doi:10.1186/1471-230X-8-39

This article is available from: http://www.biomedcentral.com/I47I-230X/8/39

(c) 2008 Umgelter et al; licensee BioMed Central Ltd.

This is an Open Access article distributed under the terms of the Creative Commons Attribution License (http://creativecommons.org/licenses/by/2.0), which permits unrestricted use, distribution, and reproduction in any medium, provided the original work is properly cited.
Received: 14 January 2008

Accepted: 27 August 2008

\begin{abstract}
Background: Patients with advanced cirrhosis of the liver typically display circulatory disturbance. Haemodynamic management may be critical for avoiding and treating functional renal failure in such patients. This study investigated the effects of plasma expansion with hyperoncotic albumin solution and the role of static haemodynamic parameters in predicting volume responsiveness in patients with advanced cirrhosis.

Methods: Patients with advanced cirrhosis (Child B and C) of the liver receiving albumin substitution because of renal compromise were studied using trans-pulmonary thermodilution. Paired measurements before and after two infusions of $200 \mathrm{ml}$ of $20 \%$ albumin per patient were recorded and standard haemodynamic parameters such as central venous pressure (CVP), mean arterial pressure (MAP), systemic vascular resistance index (SVRI), cardiac index $(\mathrm{Cl})$ and derived variables were assessed, including global end-diastolic blood volume index (GEDVI), a parameter that reflects central blood volume

Results: 100 measurements in 50 patients $(33 \mathrm{~m} / \mathrm{I} 7 \mathrm{w}$; age 56 years $( \pm 8)$; Child-Pugh-score $12( \pm 2)$, serum creatinine $256 \mu \mathrm{mol}( \pm 150)$ were analyzed. Baseline values suggested decreased central blood volumes GEDVI $=675 \mathrm{ml} / \mathrm{m}^{2}( \pm$ I38) despite CVP within the normal range $(\mathrm{II} \mathrm{mmHg}( \pm 5)$. After infusion, GEDVI, $\mathrm{Cl}$ and CVP increased $\left(682 \mathrm{ml} / \mathrm{m}^{2}( \pm 128)\right.$ vs. $744 \mathrm{ml} / \mathrm{m}^{2}( \pm 17 \mathrm{I}), \mathrm{p}<0.001 ; 4.3 \mathrm{~L} / \mathrm{min} / \mathrm{m}^{2}( \pm \mathrm{I} . \mathrm{I})$ vs. $4.7 \mathrm{~L} / \mathrm{min} / \mathrm{m}^{2}( \pm \mathrm{I} . \mathrm{I}), \mathrm{p}<0.00 \mathrm{I} ; 12 \mathrm{mmHg}( \pm 6)$ vs. $14 \mathrm{mmHg}( \pm 6), \mathrm{p}<0.001$ respectively) and systemic vascular resistance decreased $\left(1760 \mathrm{dyn} \mathrm{s} / \mathrm{cm}^{5} / \mathrm{m}^{2}( \pm 1 / 44)\right.$ vs. $\left.1490 \mathrm{dyn} \mathrm{s} / \mathrm{cm}^{5} / \mathrm{m}^{2}( \pm 837) ; p<0.00 \mathrm{I}\right)$. Changes in GEDVI, but not CVP, correlated with changes in $\mathrm{Cl}\left(r^{2}=0.5 \mathrm{I} ; \mathrm{p}<0.00 \mathrm{I}\right)$. To assess the value of static haemodynamic parameters at baseline in predicting an increase in $\mathrm{Cl}$ of $10 \%$, receiver-operatingcharacteristic curves were constructed. The areas under the curve were $0.766(p<0.00 I)$ for SVRI, 0.723 $(p<0.00 \mathrm{I})$ for $\mathrm{Cl}, 0.652(p=0.010)$ for CVP and $0.616(p=0.050)$ for GEDVI.

Conclusion: In a substantial proportion of patients with advanced cirrhosis, plasma expansion results in an increase in central blood volume. GEDVI but not CVP behaves as an indicator of cardiac preload, whereas high baseline SVRI is predictive of fluid responsiveness.
\end{abstract}




\section{Background}

Patients with advanced cirrhosis of the liver characteristically suffer from circulatory disturbance [1]. Portal hypertension leads to mesenteric vasodilation. Peripheral vascular resistance is decreased and a hyperdynamic circulation ensues. Due to the pooling of blood in the splanchnic vessels, central blood volume is diminished [2] and endogenous vasopressor systems are activated in compensation [3]. These patients are vulnerable to further haemodynamic insults and, if renal auto-regulation is overwhelmed, acute kidney failure is a common complication [4]. This is termed hepatorenal syndrome (HRS), if renal failure is advanced (serum creatinine $>133 \mu \mathrm{mol} / \mathrm{l}$ ) and if septic shock and prerenal azotaemia caused by volume losses are excluded. It negatively affects mortality [5], even if transplantation is performed [6].

The maintenance of a stable circulation is therefore important in cirrhotic patients. Plasma expansion with albumin has been found to protect against renal failure in spontaneous bacterial peritonitis [7]. It has also become a mainstay in the treatment of HRS and a prerequisite of its diagnosis, particularly when, according to a current consensus statement, "true hypovolaemia" has to be excluded by administration of a substantial amount (up to $100 \mathrm{~g}$ daily) of albumin over two days [8]. During acute conditions such as infection or haemorrhage, as well as for the treatment of functional renal failure, parameter guided fluid therapy may be useful for avoiding or improving relative hypovolemia, but also for avoiding potential complications of fluid overload. Data on the haemodynamic effects of an albumin infusion in cirrhotic patients, however, are scarce and it is not clear which parameters should be employed to guide fluid therapy in cirrhotic patients. Central venous pressure (CVP) has been shown to be of little value in the assessment of fluid responsiveness in critically ill patients [9-11]. In addition, elevated intraabdominal pressure, as seen in ascitic patients, may influence CVP [12]. It therefore is of no surprise that in a recent study the traditional target values for CVP apparently failed to exclude hypovolaemia in patients with HRS[13]. Pulmonary artery catheters have traditionally been used for guiding haemodynamic interventions. Their use however remains controversial as they may be associated with complications and their predictive value in the assessment of fluid responsiveness is low [9,14-16]. Based on earlier work on indicator dilution techniques for the measurement of cardiac output (CO) and intra-thoracic blood volumes $[17,18]$, trans-pulmonary thermodilution combined with continuous measurement of $\mathrm{CO}$ by pulse contour analysis has in recent years been evaluated $[10,11,19]$. Trans-pulmonary thermodilution has shown some promise in guiding fluid therapy by providing preload-associated parameters such as the global enddiastolic volume (GEDV). A treatment protocol targeting
GEDV assessed by trans-pulmonary thermodilution resulted in reduced need for catecholamines and less time on mechanical ventilation in cardiac surgery patients [20].

It is, however, questionable if results from studies in noncirrhotic patients are to be extrapolated to cirrhotic patients. Earlier studies found that central blood volume in cirrhotic patients cannot be significantly expanded, thus casting doubt on possible correlations between intrathoracic blood-volumes, as a measure of preload, and CO $[21,22]$. To date, trans-pulmonary thermodilution has only been evaluated in ventilated cirrhotic patients during orthotopic transplantation of the liver [23].

The aim of this present study was to investigate the haemodynamic response to volume loading with hyperoncotic albumin solution, and to compare CVP and volumetric measures as markers of preload, and predictors of fluid responsiveness, in cirrhotic patients.

\section{Methods}

The institutional ethics committee (Ethikkommission des Klinikums Rechts der Isar der Technischen Universität München) considered the protocol part of clinical routine and waived the need for informed written consent. Written consent was obtained for the publication of data.

\section{Patients}

Patients with cirrhosis Child-Pugh-Class B or C and ascites grade II or III treated in our ICU were included. Albumin substitution was prescribed according to our internal standards because of the risk of kidney failure as defined by the RIFLE criteria (acute increase in serum creatinine of 1.5 times baseline or oliguria of $<0.5 \mathrm{ml} / \mathrm{kg} / \mathrm{h}$ for at least 6 hours), or established renal failure along with indicators of pre-renal kidney failure (fractional excretion of sodium $<1 \%$ and no evidence of pre-existing renal impairment). To be included, patients had to already be instrumented with a thermodilution arterial line and a central venous catheter. Exclusion criteria were sepsis diagnosed by clinical criteria, and, if appropriate, chest $\mathrm{x}$-rays, blood or urine cultures, and current haemorrhage. Patients receiving vasoactive or cardiotropic drugs were also excluded, as were mechanically ventilated patients.

Albumin substitution was prescribed according to our treatment standards for cirrhotic patients with pre-renal kidney failure as suggested by the recent literature [8].

\section{Haemodynamic Measurements}

Patients were studied in a supine position, with zero pressure at the midaxillary line. CVP was recorded at end-expiration; thermodilution measurements using $15 \mathrm{ml}$ of icecold saline were recorded in triplicate using a commercially available device (PiCCO; Pulsion Medical Systems, 
Munich, Germany) and their average recorded. Briefly, transpulmonary thermodilution works when a bolus of cold saline solution is injected via a central line (usually located in the superior vena cava) and detected downstream by a thermistor at the tip of the femoral arterial catheter. CO is calculated by the analysis of the thermodilution curve using the Stewart-Hamilton algorithm. Mean transit time and exponential downslope time of the thermodilution curve are also analysed. The product of $\mathrm{CO}$ and mean transit time is the volume of distribution of the thermal indicator, or "intra-thoracic thermal volume" comprising of the intra-thoracic blood volume and the extravascular lung water. The product of $\mathrm{CO}$ and exponential downslope time is the "pulmonary thermal volume" composed of the pulmonary blood volume and the extravascular lung water. The GEDV is obtained as the difference between intra-thoracic thermal volume and pulmonary thermal volume [24].

Values for mean arterial pressure (MAP), CVP, CO, Systemic Vascular Resistance (SVR), GEDV, Stroke Volume (SV) and Heart Rate (HR) were obtained, and, when appropriate, indexed to an estimate of body surface area (BSA), according to the formula of duBois, to calculate Cardiac Index (CI), Global End-diastolic Volume Index (GEDVI), Systemic Vascular Resistance Index (SVRI) and Stroke Volume Index (SVI). Stroke volume divided by pulse pressure was used as a marker for arterial compliance and calculated as follows: compA $=$ SV/(RRsys RRdia) [25]. Cardiac power index was calculated as CPI = $\mathrm{CI} \times \mathrm{MAP} / 451$ [26].

\section{Study Protocol}

Haemodynamic measurements were performed immediately before infusion of a bolus of $200 \mathrm{ml} \mathrm{20 \%}$ albumin solution over a short time period $(<30 \mathrm{~min})$. Measurement of haemodynamic variables were repeated 1 hour after the start of infusion, to allow for maximal plasma expansion. Albumin infusions were prescribed by the treating physician and were administered as aliquots of $200 \mathrm{ml} \mathrm{20 \%}$ solution ( $40 \mathrm{~g}$ of albumin). For statistical reasons, only the first two measurements after inclusion for each patient were analysed.

\section{Statistical analysis}

Data were assessed for normal distribution using the Kolmogorov-Smirnov test. Normal distribution was found for all haemodynamic parameters. Accordingly, data are presented as mean $( \pm \mathrm{SD})$. Haemodynamic parameters before and after albumin infusion were compared using Students T-test for paired samples.

Parameters displaying significant changes in univariate analysis were evaluated for correlations with Pearson's test.
A positive response to volume loading was defined as an increase in $\mathrm{CI}$ of $>10 \%$. This value was chosen for the following reasons: Previous studies investigating fluid responsiveness have used cut-off values for CI of $10-20 \%$ [16]. Reproducibility of measurements of $\mathrm{CO}$ and GEDV have been found to be $4 \pm 2 \%$ and $5 \pm 2 \%$, respectively, and increases after plasma expansion of an amount similar to our study previously resulted in mean increases in cardiac output of $7-15 \%$ [22].

Responders and non-responders were compared using the Student T test for unpaired samples. For baseline haemodynamic parameters that were significantly different between responders and non-responders, ROC curves were constructed to analyse their respective value to predict an increase of CI by $>10 \%$ after volume loading.

\section{Results \\ Baseline parameters}

50 consecutive patients were included between August 2005 and January 2007. Baseline characteristics are presented in Table 1. Significant correlations were found between baseline values of GEDVI and CI $\left(\mathrm{r}^{2}=0.20 ; \mathrm{p}=\right.$ $0.001)$ and between baseline values of GEDVI and SVI ( $\mathrm{r}^{2}$ $=0.28 ; \mathrm{p}<0.001$ ).

\section{Haemodynamic effects of fluid loading}

Haemodynamic parameters obtained before and after 100 albumin infusions were analysed and are presented in Table 2. In 43 cases there was an increase in CI of $>10 \%$ after albumin infusion.

Table I: Baseline characteristics of all patients

\begin{tabular}{|c|c|}
\hline Age (years) & $56( \pm 8)$ \\
\hline Gender $(\mathrm{m} / \mathrm{f})$ & $33 / 17$ \\
\hline MELD-score & $28( \pm 9)$ \\
\hline Child-Pugh-score & $12( \pm 2)$ \\
\hline Child-Pugh class $(\mathrm{B} / \mathrm{C})$ & $10 / 40$ \\
\hline Serum creatinine $(\mu \mathrm{mol} / \mathrm{l})$ & $256( \pm 150)$ \\
\hline Fractional excretion of Sodium (\%) & $0.040( \pm 0.026)$ \\
\hline Creatinine clearance $(\mathrm{ml} / \mathrm{min})$ & $22( \pm 16)$ \\
\hline $\mathrm{CVP}(\mathrm{mmHg})$ & $11( \pm 5)$ \\
\hline GEDVI (ml/m²); (n: 680-800) & $675( \pm 138)$ \\
\hline $\mathrm{Cl}\left(\mathrm{L} / \mathrm{min} / \mathrm{m}^{2}\right) ;(\mathrm{n}: 3-5)$ & $4.1( \pm 1.2)$ \\
\hline SVI $\left(\mathrm{ml} / \mathrm{m}^{2}\right) ;(\mathrm{n}: 40-60)$ & $48( \pm 13)$ \\
\hline $\mathrm{HR}(\mathrm{bpm})$ & $88( \pm 20)$ \\
\hline SVRI (dyn s/cm5/m²); (n:I700-2400) & $1898( \pm 1015)$ \\
\hline $\operatorname{compa}_{\mathrm{a}}(\mathrm{ml} / \mathrm{mmHg})$ & $1.58( \pm 0.57)$ \\
\hline $\operatorname{MAP}(\mathrm{mmHg})$ & $79( \pm 14)$ \\
\hline $\mathrm{CPI}\left(\mathrm{mmHg} \mathrm{L} / \mathrm{min} / \mathrm{m}^{2}\right)$ & $0.71( \pm 0.27)$ \\
\hline
\end{tabular}

MELD: Model of End-Stage Liver Disease; CVP: Central Venous Pressure; GEDVI: Global End-Diastolic Volume Index; $\mathrm{Cl}$ : Cardiac Index; SVI: Stroke Volume Index; HR: Heart Rate; SVRI: Systemic Vascular Resistance Index; comp: Arterial Compliance; MAP: Mean Arterial Pressure; CPI: Cardiac Power Index 
Table 2: Haemodynamic parameters before and after infusion of $200 \mathrm{ml}$ of $20 \%$ albumin solution.

\begin{tabular}{|c|c|c|c|}
\hline & Before & after & \\
\hline CVP $(\mathrm{mmHg})$ & $12( \pm 6)$ & $14( \pm 6)$ & $\begin{array}{l}\mathrm{P}<0.00 \mathrm{I} \\
95 \% \mathrm{Cl} \mathrm{I}-3\end{array}$ \\
\hline GEDVI (ml/m²); (n: 680-800) & $682( \pm 128)$ & $744( \pm|7|)$ & $\begin{array}{l}\mathrm{P}<0.001 \\
95 \% \mathrm{Cl} 38-87\end{array}$ \\
\hline $\mathrm{Cl}\left(\mathrm{L} / \mathrm{min} / \mathrm{m}^{2}\right) ;(\mathrm{n}: 3-5)$ & $4.3( \pm 1.1)$ & $4.7( \pm \mathrm{I} .1)$ & $\begin{array}{l}\mathrm{p}<0.001 \\
95 \% \mathrm{Cl} 0.3-0.5\end{array}$ \\
\hline SVI (ml/m²); (n: 40-60) & $49( \pm 12)$ & $54( \pm 13)$ & $\begin{array}{l}\mathrm{p}<0.001 \\
95 \% \mathrm{Cl} 2-6\end{array}$ \\
\hline HR (bpm) & $89( \pm 18)$ & $90( \pm 16)$ & $\begin{array}{l}P=0.816 \\
95 \% \mathrm{Cl}-3-1\end{array}$ \\
\hline SVRI (dyn s/cm5/m²); (n: I700-2400) & $1760( \pm$ I I44) & $1490( \pm 837)$ & $\begin{array}{l}p<0.001 \\
95 \% \mathrm{Cl}-370--170\end{array}$ \\
\hline compA (ml/mmHg) & $1.59( \pm 0.52)$ & $1.70( \pm 0.62)$ & $\begin{array}{l}p=0.040 \\
95 \% \mathrm{Cl}-0.21-0.02\end{array}$ \\
\hline MAP $(\mathrm{mmHg})$ & $78( \pm 12)$ & $80( \pm 13)$ & $\begin{array}{l}p=0.310 \\
95 \% \mathrm{Cl}-\mathrm{I}-4\end{array}$ \\
\hline $\mathrm{CPI}\left(\mathrm{mmHg} \mathrm{L} / \mathrm{min} / \mathrm{m}^{2}\right)$ & $0.72( \pm 0.27)$ & $0.81( \pm 0.31)$ & $\begin{array}{l}\mathrm{P}<0.00 \mathrm{I} \\
95 \% \mathrm{Cl} 0.06-0.13\end{array}$ \\
\hline
\end{tabular}

CVP: Central Venous Pressure; GEDVI: Global End-Diastolic Volume Index; Cl: Cardiac Index; SVI: Stroke Volume Index; HR: Heart Rate; SVRI: Systemic Vascular Resistance Index; compa: Arterial Compliance; MAP: Mean Arterial Pressure; CPI: Cardiac Power Index

\section{Correlations between changes in haemodynamic parameters}

Changes in $\mathrm{CI}$ following volume challenges showed significant correlations with changes in GEDVI $\left(\mathrm{r}^{2}=0.51 ; \mathrm{p}\right.$ $<0.001)$, but not with changes in CVP $\left(\mathrm{r}^{2} 0.01, \mathrm{p}=0.45\right)$ or MAP $\left(r^{2}=0.01 ; p=0.26\right)$. Likewise, changes in SVI were correlated with changes in GEDVI $\left(\mathrm{r}^{2}=0.27 ; \mathrm{p}<0.001\right)$ but not with changes in CVP or MAP. As expected, there was an inverse correlation between CI and SVRI $\left(\mathrm{r}^{2}=0.21\right.$, $\mathrm{p}<0.001$ ), but no correlation between CI or GEDVI and MAP.

\section{Predictors of fluid responsiveness}

In responders CVP, GEDVI, SVI and CI were significantly lower than in non-responders, whereas SVRI was significantly higher (Table 3 ).

ROC-Curves for GEDVI, CVP and SVRI are displayed in Figure 1. Area under the curve was greatest for SVRI (area $0.766 ; \mathrm{p}<0.001,95 \% \mathrm{CI} 0.674-0.859$ ) and CI (area $0.723 ; \mathrm{p}<0.001,95 \% \mathrm{CI} 0.629-0.816)$, still significantly better than chance (area $=0.5$ ) for CVP (area 0.652; $\mathrm{p}=$ $0.010,95 \% \mathrm{CI} 0.542-0.761)$ and bordering significance

Table 3: Differences in pre-infusion haemodynamic parameters between responders and non-responders

\begin{tabular}{|c|c|c|c|}
\hline & responders & non-responders & \\
\hline CVP $(\mathrm{mmHg})$ & $10( \pm 4)$ & $13( \pm 6)$ & $\begin{array}{l}\mathrm{p}<0.00 \mathrm{I} \\
95 \% \mathrm{Cl} \mathrm{I}-3\end{array}$ \\
\hline GEDVI (ml/m²); (n: 680-800) & $638( \pm 135)$ & $714( \pm 117)$ & $\begin{array}{l}p<0.001 \\
95 \% \mathrm{Cl} 38-87\end{array}$ \\
\hline $\mathrm{Cl}\left(\mathrm{L} / \mathrm{min} / \mathrm{m}^{2}\right) ;(\mathrm{n}: 3-5)$ & $3.7( \pm 1.0)$ & $4.7( \pm 1.0)$ & $\begin{array}{l}p<0.001 \\
95 \% \mathrm{Cl} 0.3-0.5\end{array}$ \\
\hline $\mathrm{SVI}\left(\mathrm{ml} / \mathrm{m}^{2}\right) ;(\mathrm{n}: 40-60)$ & $45( \pm 14)$ & $54( \pm 9)$ & $\begin{array}{l}\mathrm{P}<0.00 \mathrm{I} \\
95 \% \mathrm{Cl} 2-6\end{array}$ \\
\hline HR (bpm) & $90( \pm 15)$ & $86( \pm 19)$ & $\begin{array}{l}p=0.816 \\
95 \% \mathrm{Cl}-3-1\end{array}$ \\
\hline SVRI (dyn s/cm5/m²); (n:I700-2400) & $2262( \pm 1323)$ & $1390( \pm 648)$ & $\begin{array}{l}P<0.001 \\
95 \% \mathrm{Cl}-370--170\end{array}$ \\
\hline compA (ml/mmHg) & $1.49( \pm$ & $\mathrm{I} .68( \pm 0.56)$ & $\begin{array}{l}P=0.040 \\
95 \% \mathrm{Cl}-0.20-0.02\end{array}$ \\
\hline MAP $(\mathrm{mmHg})$ & $78( \pm 13)$ & $80( \pm 13)$ & $\begin{array}{l}p=0.310 \\
95 \% \mathrm{Cl}-1-4\end{array}$ \\
\hline $\mathrm{CPI}\left(\mathrm{mmHg} \mathrm{L} / \mathrm{min} / \mathrm{m}^{2}\right)$ & $0.71( \pm 0.27)$ & $0.81( \pm 0.32)$ & $\begin{array}{l}\mathrm{P}<0.00 \mathrm{I} \\
95 \% \mathrm{Cl} 0.06-0.12\end{array}$ \\
\hline
\end{tabular}

CVP: Central Venous Pressure; GEDVI: Global End-Diastolic Volume Index; Cl: Cardiac Index; SVI: Stroke Volume Index; HR: Heart Rate; SVRI: Systemic Vascular Resistance Index; compa: Arterial Compliance; MAP: Mean Arterial Pressure; CPI: Cardiac Power Index 


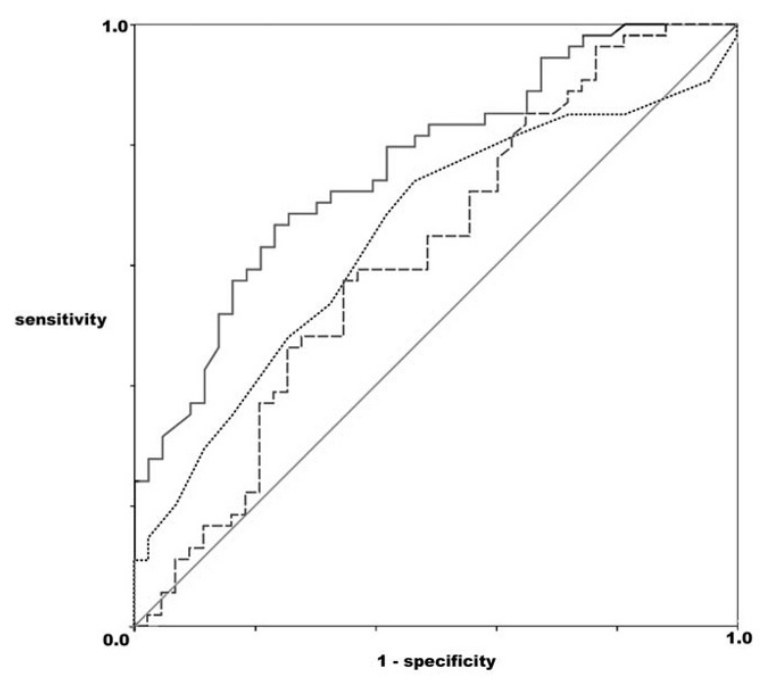

Figure I

Receiver operating characteristic curves for systemic vascular resistance index (continuous line), central venous pressure (dotted line) and global and-diastolic volume index (broken line). The diagonal line is the line of no-discrimination.

for GEDVI (area 0.616; $\mathrm{p}=0.050$ ), 95\%CI $0.501-0.731$ ). For SVRI a cut-off value of 1270 dyne $\cdot \mathrm{s} / \mathrm{cm}^{5} / \mathrm{m}^{2}$ discriminated between responders and non-responders (sensitivity 0.67 , specificity 0.77 ). For CVP the best combined sensitivity and specificity was found for a threshold value of $10 \mathrm{mmHg}$ with 0.74 and 0.54 , respectively. For GEDVI a threshold value of $680 \mathrm{ml} / \mathrm{m}^{2}$ had a sensitivity of 0.59 and a specificity of 0.65 for predicting a positive response to albumin infusion.

\section{Discussion}

At baseline we found a GEDVI in the lower range of normal despite a relatively high CVP. CI was in the normal range and SVRI at a low normal value. These findings are in accordance with the concept suggested by the peripheral arterial vasodilation hypothesis on cirrhotic circulatory dysfunction [1]. Infusion of albumin solution resulted in an increase in GEDVI, which correlated to an increase in cardiac index that was larger than $10 \%$ in almost half the cases. This is similar to what has previously been reported in fluid resuscitation of septic patients [11]. Responders to volume loading displayed a baseline haemodynamic pattern suggestive of lower cardiac preload with less hyperdynamic circulation and higher peripheral resistance.

The improvement in CI after volume therapy supports the notion that relative central hypovolaemia contributes to circulatory dysfunction in cirrhotic patients. After plasma expansion with albumin we found an increase in central blood volume. This is in contrast to the results of other studies who failed to detect relevant changes in central blood volume after fluid loading in patients with advanced cirrhosis $[22,27]$. We believe that in these studies the possible effects were missed due to the small number of patients included. Indeed, both studies showed increases in central blood volume after volume loading, however, this failed to reach statistical significance.

In our study, baseline GEDVI correlated with baseline CI and SVI, and GEDVI was lower in patients with a positive response to volume loading than in those with a negative response. Furthermore, increases in GEDVI correlated to increases in CI and SVI, highlighting that GEDVI, evaluated by trans-pulmonary thermodilution, behaves as an indicator of preload in patients with cirrhosis. CVP was lower in patients who responded to volume loading and increased significantly after infusion. The volume loading-induced changes, however, were not proportional to the changes in CI and SVI, and baseline CVP did not correlate with CI or SVI. This confirms previous reports and underlines the limited value of CVP as a marker of cardiac preload. Both parameters performed poorly as predictors of volume responsiveness as has been previously documented in various clinical settings $[16,28]$.

Cardiac preload is defined as myocardial wall tension at end diastole, and, according to Laplace's law, is determined by ventricular geometry and intra-ventricular pressures. Myocardial contractility depends on end-diastolic tension of the myocardial sarcomers and the connection between increasing preload and contractility is given in the sigmoidal Frank-Starling curve. Without knowing the individual myocardial properties at the moment of interest, we cannot determine the position on the Frank-Starling curve of any given preload condition. This explains why good intra-individual correlations between preload markers and $\mathrm{CI}$ in paired measurements may be accompanied by a low predictive value of single measurements of preload associated markers for fluid responsiveness.

Following volume challenges we observed substantial decreases in SVRI in our patients. SVRI is dependant on (MAP-CVP) and CI by a linear relationship. Therefore, with constant CVP, any changes in CI must be accompanied by proportional changes in SVRI, MAP, or both. In patients with septic shock, opposite changes of a similar relative size of both MAP and SVRI have been observed after volume loading [11]. In contrast, we found large decreases in SVRI with only minuscule increases in MAP. This contrasts to a previous study on plasma expansion in patients with spontaneous bacterial peritonitis (SBP) 
[29]. Here the authors described an increase in peripheral vascular resistance after treatment of SBP with antibiotics and albumin. They hypothesized that this may be due to the pharmacological action of albumin as a scavenger of nitric oxide, thus reducing the vasodilatory properties of plasma. However, haemodynamic measurements in this study were days apart and the increased vasotonus, may have been due to reduced septic vasodilation. In our study cohort, care was taken to select patients without infection or haemorrhage, so that any related confounding factors were avoided.

Whereas MAP was not different between the patients who responded to volume loading and those who did not, SVRI was significantly and by a large proportion higher in responders when compared to non-responders. However, CI was significantly lower in responders than in nonresponders. Pre-infusion values of SVRI (and CI) were predictive of volume responsiveness in our patients. As suggested previously [30], this may indicate that in a proportion of patients with cirrhotic circulatory dysfunction, relative central hypovolaemia, resulting in further activation of endogenous vasopressor systems to maintain MAP at the cost of high peripheral resistance, may contribute to impaired cardiac output, despite what is essentially a hyperdynamic circulation. Volume therapy may thus decrease vasopressor activation, and may lead to decreased levels of endogenous vasopressors such as norepinephrine, renin and angiotensin, as has been described previously [22]. Renal dysfunction in cirrhosis deteriorates along a continuum starting with an impaired capacity to excrete sodium and free water leading to an oedematous state with increased plasma volume and ascites, to pre-renal failure and, finally, irreversible tubular damage. According to current understanding, an important etiologic factor is elevated levels of vasoconstrictors affecting the renal microcirculation, narrowing the kidneys' capacity to cope with additional haemodynamic insults. Volume management may be relevant to the prevention and treatment of functional renal failure in cirrhosis. Recent studies on vasopressor therapy in HRS highlight the importance of adequate volume status. Whereas it had previously been shown that albumin was necessary for the beneficial effect of terlipressin [31], a recent study by Alessandria et al. showed that a substantial number of patients included in a study on treatment of HRS responded to plasma expansion alone when it was tailored according to CVP instead of using the usual fixeddose regimen [13]. In this study the aim was a CVP of 10 - $15 \mathrm{mmHg}$. In our study, 33\% of patients with a CVP greater than $10 \mathrm{mmHg}$ and $24 \%$ of patients a CVP of over $>15 \mathrm{mmHg}$ still responded to albumin infusion with a further increase in CI. Consequently, neither CVP nor GEDVI should be recommended as parameters to direct fluid resuscitation in cirrhotic patients with pre-renal kidney failure.

In ventilated patients, dynamic parameters such as pulse pressure variation or stroke volume variation have shown much better predictive power for assessing fluid responsiveness [28]. However, the majority of cirrhotic patients at risk of renal failure are breathing spontaneously and these circumstances, dynamic parameters are not applicable. A time honoured method for the assessment of fluid responsiveness, "passive leg raising" (PLR) [32], has recently gained renewed interest in the intensive care setting. PLR generates a transient increase in venous return. The immediate haemodynamic response of mean blood flow to this manoeuvre, assessed by methods such as oesophageal Doppler [33] or trans-thoracic echocardiography [34], has been used to estimate fluid responsiveness. The recently published method of PLR is difficult to apply in the intensive care setting, because a fixed angle of the hips is required throughout the procedure and the whole bed must be tilted instantaneously by $45^{\circ}$. Cirrhotic patients may react differently to tilting than other patients or normal controls [35], and the elevated intraabdominal pressure of ascitic patients may also affect PLRinduced blood transfer [36]. Therefore, PLR may give different results in cirrhotic patients. This has not to our knowledge been evaluated.

Without static parameters predictive of fluid responsiveness, but a variety of monitoring tools capable of providing data on $\mathrm{CI}$ and MAP, iterative protocols of fluid challenges may offer the possibility of increasing cardiac output in patients with reduced effective intravascular volume [14]. Whether this translates to improved kidney function in cirrhotic patients with renal failure should be evaluated in future studies.

The obvious limitations of our study are the uncontrolled design and the use of albumin solution instead of crystalloid solutions for the volume challenge. Hyperoncotic albumin solution acts as a plasma expander and, in addition, has distinct pharmacological properties.

\section{Conclusion}

In contrast to earlier studies we have observed a significant increase in central blood volume and CI after albumin infusion in a substantial proportion of patients with advanced cirrhosis. In contrast to CVP, GEDVI behaved as a preload indicator, but neither parameter was able to predict fluid responsiveness with acceptable accuracy. After albumin infusion there were no relevant changes in MAP, but large decreases in SVRI. Pre-infusion SVRI and CI discriminated between patients with and without a positive response in CI to volume loading. Circulatory dysfunction in cirrhotic patients with pre-renal kidney failure may be 
amenable to plasma expansion and future trials to evaluate fluid resuscitation strategies in these patients are warranted.

\section{Competing interests}

WH and AU have been invited speakers for Pulsion Medical Systems, Munich; the other authors declare no competing interests. No grants or external funding were received for this study.

\section{Authors' contributions}

AU, KW and WR: Idea and design of the study. AU, KW, NN, WR: Collection and analysis of data. AU wrote the manuscript. WH and RMS revised and co-wrote the manuscript.

\section{Acknowledgements}

We want to express our gratitude for the support obtained by the nursing staff of the intensive care unit of the $2^{\text {nd }}$ Medical Department of the Klinikum rechts der Isar.

We thank Harriet Adamson for editing the manuscript.

\section{References}

I. Schrier RW, Arroyo V, Bernardi M, Epstein M, Henriksen JH, Rodes $\mathrm{J}$ : Peripheral arterial vasodilation hypothesis: a proposal for the initiation of renal sodium and water retention in cirrhosis. Hepatology 1988, 8: ||5|-II57.

2. Henriksen JH, Bendtsen F, Sørensen TI, Stadeager C, Ring-Larsen H: Reduced central blood volume in cirrhosis. Gastroenterology 1989, 97:1506-1513.

3. Ruiz-del-Arbol L, Monescillo A, Arocena C, Valer P, Gines P, Moreira V, Milicua JM, Jimenez W, Arroyo V: Circulatory Function and Hepatorenal Syndrome in Cirrhosis. Hepatology 2005, 42:439-447.

4. Epstein M, Berk DP, Hollenberg NK, Adams DF, Chalmers TC Abrams HL, Merrill JP: Renal failure in the patient with cirrhosis. Am J Med 1970, 49:175-185.

5. Cheyron D, Bouchet B, Parienti IJ, Ramakers M, Charbonneau P: The attributable mortality of acute renal failure in critically ill patients with liver cirrhosis. Intensive Care Medicine 2005, 3I:1693-1699.

6. Moreau $\mathrm{R}$ : The growing evidence that renal function should be improved in patients with cirrhosis and hepatorenal syndrome before liver transplantation. J Hepatol 2004, 40: I59-16I.

7. Sort P: Effect of intravenous albumin on renal impairment and mortality in patients with cirrhosis and spontaneous bacterial peritonitis. N Engl ] Med 1999, 341:403-409.

8. Salerno $F$, Gerbes $A$, Ginès $P$, Wong $F$, Arroyo V: Definition, diagnosis and treatment of hepatorenal syndrome in cirrhosis. $A$ consensus workshop of the international ascites club. Gut 2007, 56: $|3| 0-13 \mid 8$.

9. Kumar A, Anel R, Bunnell E, Habet K, Zanotti S, Marshall S, Neumann A, Ali A, Cheang M, Kavinsky C, Parrillo JE: Pulmonary artery occlusion pressure and central venous pressure fail to predict ventricular filling volume, cardiac performance, or the response to volume infusion in normal subjects. Crit Care Med 2004, 32:691-699.

10. Goedje O, Peyerl M, Seebauer T, Lamm P, Mair H, Reichart B: Central venous pressure, pulmonary capillary wedge pressure and intrathoracic blood volumes as preload indicators in cardiac surgery patients. Eur J Cardiothorac Surg 1998, 13:533-539.

11. Michard F, Alaya S, Zarka V, Bahloul M, Richard Ch, Teboul JL: Global End-diastolic volume as an indicator of cardiac preload in patients with septic shock. Chest 2003, I 24:1900-1908.

12. Zollinger A, Krayer S, Singer T, Seifert B, Heinzelmann M, Schlumpf $R$, Pasch $T$ : Haemodynamic effects of pneumoperitoneum in elderly patients with an increased cardiac risk. Eur J Anaesthesiol 1997, I 4:266-75.

13. Alessandria C, Ottobrelli A, Debernardi-Venon W, Todros L, Cerenzia MT, Martini S, Balzola F, Morgando A, Rizzetto M, Marzano A: Noradrenalin vs terlipressin in patients with hepatorenal syndrome: A prospective, randomized, unblinded, pilot study. Journal of Hepatology 2007, 47:499-505.

14. Marik PE: Assessment of intravascular volume: a comedy of errors. Crit Care Med 200I, 29:1635-1636.

15. Raper R, Sibbald WJ: Misled by the wedge? the Swan-Ganz catheter and left ventricular preload. Chest 1986, 89:427-434.

16. Michard F, Theboul JL: Predicting fluid responsiveness in ICU patients: a critical analysis of the evidence. Chest 2002, | 2 1:2000-2008

17. Newman EV, Merrell M, Genecin A, Monge C, Milnor WR, McKeever WP: The dye dilution method for describing the central circulation. An analysis of factors shaping the time-concentration curves. Circulation 195I, 4:735-746.

18. Meier $\mathrm{P}$, Zierler $\mathrm{KL}$ : On the theory of indicator-dilution method for measurement of blood flow and volume. J Appl Physiol 1954, 6:73I-744.

19. Goedje O, Hoeke K, Lichtwarck-Aschoff M, Faltchauser A, Lamm P, Reichart B: Continuous cardiac output by femoral arterial thermodilution calibrated pulse contour analysis: comparison with pulmonary arterial thermodilution. Crit Care Med 1999, 27:2407-2412.

20. Goepfert MS, Reuter DA, Akyol D, Lamm P, Kilger E, Goetz AE: Goal-directed fluid management reduces vasopressor and catecholamine use in cardiac surgery patients. Intensive Care Med 2007, 33:96-103.

21. Henriksen JH, Kiszka-Kanowitz M, Bendtsen F, Moller S: Review article: volume expansion in patients with cirrhosis. Aliment Pharmacol Ther 2002, 16 Suppl 5:12-23.

22. Brinch K, Moller S, Bendtsen F, Becker U, Henriksen J: Plasma volume expansion by albumin in cirrhosis. Relation to blood volume distribution, arterial compliance and severity of disease. Journal of Hepatology 2003, 39:24-3I.

23. Della Rocca G, Costa MG, Coccia C, Pompei L, Pietropaoli P: Preload and haemodynamic assessment during liver transplantation: a comparison between the pulmonary artery catheter and transpulmonary indicator dilution techniques. Eur J Anaesthesiol 2002, 19:868-875.

24. Sakka SG, Ruhl CC, Pfeiffer UJ, Beale R, McLuckie A, Reinhart K Meier-Hellmann A: Assessment of cardiac preload and extravascular lung water by single transpulmonary thermodilution. Intensive Care Med 2000, 26: I80-I87.

25. Henriksen JH, Fuglsang S, Bendtsen F, Christensen E, Møller S: Arterial compliance in patients with cirrhosis: stroke volumepulse pressure ratio as simplified index. Am J Physiol Gastrointest Liver Physiol 200 I, 280: G584-594.

26. Fincke R, Hochman JS, Lowe AM, Menon V, Slater JN, Webb JG Lejemtel TH, Cotter G: Cardiac power is the strongest hemodynamic correlate of mortality in cardiogenic shock: a report from the SHOCK trial registry. J Am Coll Cardiol 2004, 44:340-348.

27. Møller S, Bendtsen F, Henriksen J: Effect of volume expansion on systemic hemodynamics and central and arterial blood volume in cirrhosis. Gastroenterology 1995, 109:1917-1925.

28. Bendjelid K, Romand JA: Fluid responsiveness in mechanically ventilated patients: a review of indices used in intensive care. Intensive Care Med 2003, 29:352-360.

29. Fernandez J, Navasa M, Garcia-Pagan JC, G-Abraldes J, Jimenez W Bosch J, Arroyo V: Effect of intravenous albumin on systemic and hepatic hemodynamics and vasoactive neurohormonal systems in patients with cirrhosis and spontaneous bacterial peritonitis. Journal of Hepatology 2004, 41 :384-390.

30. Lenz K: Hepatorenal Syndrome - Is It Central Hypovolemia, a Cardiac Disease, or Part of Gradually Developing Multiorgan Dysfunction? Hepatology 2005, 42:263-165.

31. Ortega R, Gines P, Uriz J, Cardenas A, Calahorra B, De Las Heras D, Guevara M, Bataller R, Jimenez W, Arroyo V, Rodes J: Terlipressin therapy with and without albumin for patients with hepatorenal syndrome: results of a prospective, nonrandomized study. Hepatology 2002, 36:94I-948. 
32. Thomas $M$, Shillingford J: The circulatory response to a standard postural change in ischemic heart disease. Br Heart J 1965, 27:17-27.

33. Monnet X, Rienzo M, Osman D, Anguel N, Richard C, Pinsky MR, Teboul JL: Passive leg raising predicts fluid responsiveness in the critically ill. Crit Care Med 2006, 34:1402-1407.

34. Lamia B, Ochagavia A, Monnet X, Chemla D, Richard C, Teboul JL: Echocardiographic prediction of volume responsiveness in critically ill patients with spontaneously breathing activity. Intensive Care Med 2007, 33: I I33-I I 38.

35. Møller S, Nørgaard A, Henriksen JH, Frandsen E, F. B: Effects of tilting on central hemodynamics and homeostatic mechanisms in cirrhosis. Hepatology 2004, 40:81 I-8I9.

36. Monnet X, Teboul JL: Passive leg raising. Intensive Care Med 2008, 34:659-663.

\section{Pre-publication history}

The pre-publication history for this paper can be accessed here:

http://www.biomedcentral.com/1471-230X/8/39/pre pub

Publish with Biomed Central and every scientist can read your work free of charge

"BioMed Central will be the most significant development for disseminating the results of biomedical research in our lifetime. "

Sir Paul Nurse, Cancer Research UK

Your research papers will be:

- available free of charge to the entire biomedical community

- peer reviewed and published immediately upon acceptance

- cited in PubMed and archived on PubMed Central

- yours - you keep the copyright

Submit your manuscript here:

http://www.biomedcentral.com/info/publishing_adv.asp 